\title{
Large-scale Highly Ordered Sb Nanorod Arrays Anode with High Capacity and Rate Capability for Sodium-Ion Batteries
}

\author{
Liying Liang, Yang Xu, Chengliang Wang, Liaoyong Wen, Yaoguo Fang, Yan Mi, Min Zhou, Huaping \\ Zhao, and Yong Lei*
}

\section{${ }_{5}$ Received (in $\left.X X X, X X X\right)$ Xth $X X X X X X X X X 20 X X$, Accepted Xth $X X X X X X X X X 20 X X$} DOI: $10.1039 / b 000000 x$

\begin{abstract}
Na-ion batteries are a potential substitute to Li-ion batteries for energy storage devices. However, the poor electrochemical performance, especially capacity and rate capability are the major bottlenecks to future development. Here we propose a performance-oriented electrode structure, which is 1D 10 nanostructure arrays with large-scale high ordering, well vertical alignment, and large interval spacing. Benefiting from these structure merits, a great enhancement on electrochemical performance could be achieved. To $\mathrm{Sb}$ as an example, we firstly report large-scale highly ordered $\mathrm{Sb}$ nanorod arrays with uniform large interval spacing $(190 \mathrm{~nm})$. In return for this electrode design, high ion accessibility, fast electron transport, and strong electrode integrity are presented here. Used as additive- and binder-free 15 anode for Na-ion batteries, $\mathrm{Sb}$ nanorod arrays showed a high capacity of $620 \mathrm{mAh} \mathrm{g}^{-1}$ at the 100th cycle with a retention of $84 \%$ up to 250 cycles at $0.2 \mathrm{~A} \mathrm{~g}^{-1}$, and superior rate capability for delivering reversible capacities of 579.7 and $557.7 \mathrm{mAh} \mathrm{g}^{-1}$ at 10 and $20 \mathrm{~A} \mathrm{~g}^{-1}$, respectively. A full cell coupled by P2$\mathrm{Na}_{2 / 3} \mathrm{Ni}_{1 / 3} \mathrm{Mn}_{2 / 3} \mathrm{O}_{2}$ cathode and $\mathrm{Sb}$ nanorod arrays anode was also conducted, which showed a good cycle performance up to 250 cycles, high rate capability up to $20 \mathrm{~A} \mathrm{~g}^{-1}$, and large energy density up to $130 \mathrm{Wh}$ $20 \mathrm{~kg}^{-1}$. These excellent electrochemical performances shall pave a way to develop more applications of $\mathrm{Sb}$ nanorod arrays in energy storage devices.
\end{abstract}

\section{Introduction}

Sodium-ion batteries (SIBs) have regained increasing research interests as a potential substitute to Li-ion batteries, in particular 25 for large-scale energy storage systems, due to their low cost, abundant natural resources, and relatively low redox potential. ${ }^{1,2}$ Since $\mathrm{Na}$ ions are about $55 \%$ larger in radius than $\mathrm{Li}$ ions, a steric limitation in many host structures is inevitably obtained, leading to slow insertion and extraction of $\mathrm{Na}$ ions, large volume changes, 30 and unstable solid electrolyte interphase (SEI). Therefore, it is a major challenge to find appropriate $\mathrm{Na}$ storage electrode materials or structures for high performance SIBs. ${ }^{3,4}$

It is widely accepted that vertically aligned 1D nanostructure arrays is an efficient electrode configuration to enhance the 35 electrochemical performance of batteries..$^{5-8}$ However, the majority of reported arrays still existed some defects on their electrode structure design, which seriously weakened the electrochemical performance. Those arrays showed more or less agglomerated morphology instead of perfect vertical alignment, 40 in which the joint parts tended to break since the stress existed among these nanostructures upon cycling, resulting in the pulverization and collapse of the electrode. Meanwhile, limited interval spacing in attached arrays lowered the ion transport rate to the deep portions of the electrode, which is not conducive to ${ }_{45}$ high rate capability. Although using nanostructure arrays as electrodes omits the complex process of mixing carbon black and binder, the conductivity of most of arrays is not good enough to support the electrode to finish fast charge and discharge processes and still keep high capacity and long cycle life. ${ }^{9-12}$

50 Recently, we reported a nanoimprinted AAO templating technique to fabricate 1D nanostructure arrays with perfect longrange regularity, fine size controllability, and very large area (up to $\left.\mathrm{cm}^{2}\right) .{ }^{13-15}$ Especially, using this technique, perfectly vertically aligned 1D nanostructure arrays with large interval spacing (e.g. 55 about 200 and $400 \mathrm{~nm}$ interval spacing by using different template cell size of 400 and $800 \mathrm{~nm}$, and the definition of interval spacing and cell size is shown in Scheme 1X) are achievable. However, so far, there is very few report on the end of SIBs using such 1D nanostructure arrays electrode. ${ }^{16} \mathrm{We}$ ${ }_{60}$ believe that, using these 1D nanostructure arrays with large-scale high ordering, well vertical alignment, and large interval spacing as SIBs electrode, the electrochemical performance shall usher in a great enhancement.

Taking antimony $(\mathrm{Sb})$ as an example, it has been widely ${ }_{65}$ investigated because it is cheap, abundant, and environmentally friendly. ${ }^{17}$ The abundance of $\mathrm{Sb}$ in the Earth's crust is estimated at 0.2 to 0.5 parts per million. In addition, $\mathrm{Sb}$ has been found in over 100 mineral species. $\mathrm{Sb}$ is considered a promising anode material for SIBs due to its large $\mathrm{Na}$ storage capacity of $660 \mathrm{mAh} \mathrm{g}^{-1}$, 70 good electronic conductivity, and moderate operating voltage. ${ }^{17}$ However, the practical application of $\mathrm{Sb}$ is mainly hindered by 
the massive volume changes (about 390\%) during repeated sodiation/desodiation processes. Such volume variation results in severe pulverization and subsequent loss of electrical contact within electrodes, consequently greatly decreasing the cycling life 5 and rate capability of electrodes. ${ }^{4,18}$ Indeed, pure $\mathrm{Sb}$ powders showed a high initial capacity of $624 \mathrm{mAh} \mathrm{g}^{-1}$, while the capacity abruptly decreased to less than $100 \mathrm{mAh} \mathrm{g}^{-1}$ after 25 cycles. $^{19}$

In this work, we firstly report large-scale highly ordered $\mathrm{Sb}$ nanorod arrays with uniform large interval spacing as an 10 excellent SIBs anode, fabricated by the nanoimprinted AAO templating technique with the assistance of an electrodeposition process. In such a unique architecture, some critical features are worthwhile to be noted. First, each Sb nanorod possesses uniform nanosized diameter, which could shorten $\mathrm{Na}$ ions diffusion 15 pathway. Second, Sb nanorod arrays show the perfect vertical alignment and attendant large interval spacing, which provide direct channels for electrolyte to permeate into the deep portions of arrays, then $\mathrm{Na}$ ions can fully contact $\mathrm{Sb}$ nanorods without dead angels, improving $\mathrm{Na}$ ions accessibility. Meanwhile, the

20 large interval spacing in arrays can also prevent the pulverization by facile strain relaxation during cycling. Third, $\mathrm{Sb}$ nanorods themselves as electric conductors directly connecting with the conductive $\mathrm{Au} / \mathrm{Ni}$ substrate, offering fast and accessible electrons transport, which is very beneficial to the remarkable 25 improvements on the rate capability. Finally, the good adhesion between arrays and conductive substrate can ensure the robust arrays integrity to accommodate volume changes upon cycling.

Within the expectation, in return for its pathbreaking electrode design, the as-prepared $\mathrm{Sb}$ nanorod arrays, as additive- and bind30 free anodes for SIBs, show a high capacity of $620 \mathrm{mAh} \mathrm{g}^{-1}$ at the 100th cycle with a retention of $84 \%$ up to 250 cycles, and superior rate capability for delivering reversible capacities of 579.7 and $557.7 \mathrm{mAh} \mathrm{g}^{-1}$ at 10 and $20 \mathrm{~A} \mathrm{~g}^{-1}$, respectively. To our best knowledge, this is the best electrochemical performance in 35 comparison with previously reported Sb-based anodes for SIBs (Table 1). Moreover, a full cell constructed by P2$\mathrm{Na}_{2 / 3} \mathrm{Ni}_{1 / 3} \mathrm{Mn}_{2 / 3} \mathrm{O}_{2}$ cathode and $\mathrm{Sb}$ nanorod arrays anode was also investigated, which delivered a good cycle performance up to 250 cycles, high rate capability even at $20 \mathrm{~A} \mathrm{~g}^{-1}$, and large energy 40 density up to $130 \mathrm{Wh} \mathrm{kg}^{-1}$. We believe that these excellent electrochemical performances shall arouse high attention to develop more efficient electrode structures for energy storage system.

\section{Experimental}

\section{2.1 Synthesis of nanoimprinted AAO templates}

Nanoimprinted AAO template was prepared using nanoimprinting technique followed by an anodization process. Clean high-purity (99.99\%) aluminum foil was electrochemically polished in a 1:7 (v:v) solution of $\mathrm{HClO}_{4}$ and ethanol at a voltage 50 range of $20-30 \mathrm{~V}$. The Ni imprinting stamp was placed on polished $\mathrm{Al}$ foil, and the imprinted $\mathrm{Al}$ foil was obtained using an oil pressing system under a pressure of about $10 \mathrm{kN} \mathrm{cm}^{-2}$ for 3 min. Then the anodization was carried out under a constant voltage of $160 \mathrm{~V}$ in $0.4 \mathrm{M} \mathrm{H}_{3} \mathrm{PO}_{4}$ at $5^{\circ} \mathrm{C}$ for $30 \mathrm{~min}$, in which the 55 anodization voltage was chosen to satisfy the distance periods in the imprinting stamp owing to the linear relationship $\left(2.5 \mathrm{~nm} \mathrm{~V}^{-1}\right)$ between the interpore distance $(400 \mathrm{~nm})$ and anodization potential $(160 \mathrm{~V})$. After anodization, a $50 \mathrm{~nm}$ thick layer of $\mathrm{Au}$ were evaporated by physical vapor deposition (PVD), and then a 60 thick layer of $\mathrm{Ni}$ was electrochemically deposited on the top of the AAO template with $\mathrm{Au}$ as current-carrying substrate, where $\mathrm{Au}$ was used to improve the adhesion between Ni layer and template. The backside $\mathrm{Al}$ was removed by a mixture solution of $\mathrm{CuCl}_{2}(85 \mathrm{wt} \%)$ and $\mathrm{HCl}(15 \mathrm{wt} \%)$, and then was transferred to ${ }_{65} \mathrm{H}_{3} \mathrm{PO}_{4}$ solution $\left(5 \mathrm{wt} \%\right.$ ) at $30{ }^{\circ} \mathrm{C}$ to remove the barrier layer and widen the size of the pores. The time for the barrier layer removal and pore-widening process depends on the desired sizes of pores in the AAO template. At last, a through-pore AAO template with conductive substrate was achieved.

\section{2.2 Synthesis of Sb nanorod arrays}

$\mathrm{Sb}$ nanorod arrays were electrodeposited inside the above nanoimprinted AAO templates at a constant current density of 1.0 $\mathrm{mA} \mathrm{cm}{ }^{-2}$ in an electrolytic bath containing $\mathrm{SbCl}_{3}$ and $\mathrm{C}_{6} \mathrm{H}_{5} \mathrm{Na}_{3} \mathrm{O}_{7} \cdot 2 \mathrm{H}_{2} \mathrm{O}$. The electrodeposition was conducted in a two75 electrode cell with AAO template as the working electrode and $\mathrm{Pt}$ foil as counter electrode. Sb nanorod arrays are released by dissolving the AAO template in a $\mathrm{NaOH}$ solution $(3.0 \mathrm{M})$ for 30 min, followed by a rinsing process with deionized water. As reference samples, A-Sb NRs, A-2-Sb NRs, and A-2-Sb NRs 80 were also prepared using the similar procedures.

\subsection{Synthesis of layered $\mathrm{P2}-\mathrm{Na}_{2 / 3} \mathrm{Ni}_{1 / 3} \mathrm{Mn}_{2 / 3} \mathrm{O}_{2}$}

The $\mathrm{P} 2-\mathrm{Na}_{2 / 3} \mathrm{Ni}_{1 / 3} \mathrm{Mn}_{2 / 3} \mathrm{O}_{2}$ was prepared by a co-precipitation method with nickel and manganese nitrates in a stoichiometric amount with sodium hydroxide. $\mathrm{Na}_{2} \mathrm{CO}_{3}$ was added afterwards as 85 the sodium source. The calcinations were taken at $600{ }^{\circ} \mathrm{C}$ for $4 \mathrm{~h}$ and $900{ }^{\circ} \mathrm{C}$ for $10 \mathrm{~h}$ in air. ${ }^{20-22}$

\subsection{Characterization}

SEM and TEM measurements were performed on a Hitachi $\mathrm{S} 4800$ instrument with voltages of $5 \mathrm{kV}$ and $30 \mathrm{kV}$, respectively. 90 HRTEM measurement was performed on a Tecnai 20 S-Twin from Philips. XRD measurement was carried out on a Bruker-axs Discover D8 applying $\mathrm{Cu} \mathrm{K \alpha}(1.54056 \AA)$ radiation equipment. For post-cycling SEM measurement, $\mathrm{Sb}$ nanorod arrays electrodes after electrochemical cycling tests were carefully ${ }_{95}$ disassembled and washed with PC solution in glove box, and dried at $60^{\circ} \mathrm{C}$ in a vacuum oven. For HRTEM tests, the samples were scraped from the substrate and dispersed in ethanol followed by ultra-sonication.

\subsection{Electrochemical Measurements}

100 Electrochemical measurements of half cells were taken using CR2032 coin-type cells with sodium metal as both counter and reference electrode. Sb nanorod arrays were used anodes without any additives of conductive carbon and binder. The mass loading of the active material is around $0.4 \mathrm{mg} \mathrm{cm}^{-2}$. P2${ }_{105} \mathrm{Na}_{2 / 3} \mathrm{Ni}_{1 / 3} \mathrm{Mn}_{2 / 3} \mathrm{O}_{2}$ was employed as cathode which was prepared by mixing $80 \% \mathrm{P} 2-\mathrm{Na}_{2 / 3} \mathrm{Ni}_{1 / 3} \mathrm{Mn}_{2 / 3} \mathrm{O}_{2}, 10 \%$ acetylene black, and $10 \%$ poly(vinylidene fluoride) (PVDF) by weight with an appropriate amount of 1-methyl-2-pyrrolidinone (NMP). The above mixture was pressed onto an aluminum foil which served 110 as a current collector with a subsequent drying process at $120^{\circ} \mathrm{C}$ 
in vacuum for $12 \mathrm{~h}$. The coin batteries were assembled in a nitrogen-filled glove box with a glass fiber separator (Whatman, $\mathrm{GFB} / 55$ ) and the electrolyte solution of $1.0 \mathrm{M} \mathrm{NaClO}_{4}$ in EC: PC (1:1 by volume) with the addition of $5 \%$ fluoroethylene carbonate 5 (FEC). Cyclic voltammetry (CV) was tested on a BioLogic VSP potentiostat. Electrochemical impedance spectroscopy (EIS) was also conducted on a BioLogic VSP potentiostat with frequency of $1 \mathrm{MHz}$ to $10 \mathrm{mHz}$ at the discharge state $(0.01 \mathrm{~V})$ after the $1 \mathrm{st}$, 20th, and 50th cycle. The galvanostatic charge-discharge tests 10 were performed at various current densities on LAND-CT2001A test system (Wuhan, China). All of these experiments were conducted at room temperature.

The full cell was assembled using an electrolyte solution of 1.0 $\mathrm{M} \mathrm{NaClO}_{4}$ in EC: PC (1:1 by volume) with $5 \% \mathrm{FEC}$ and 15 galvanostatically cycled with the voltage range of 4.0 to $1.4 \mathrm{~V}$ at a current density of $0.5 \mathrm{~A} \mathrm{~g}^{-1}$ (respect to the anode mass). To ensure a suitable positive-to-negative $(\mathrm{P} / \mathrm{N})$ capacity ratio for proper cell balance, the $\mathrm{P} 2-\mathrm{Na}_{2 / 3} \mathrm{Ni}_{1 / 3} \mathrm{Mn}_{2 / 3} \mathrm{O}_{2}$ to $\mathrm{Sb}$ nanorod arrays mass loading ratio was about 18 .

\section{${ }_{20}$ 3. Results and Discussion}

The sample preparation procedure is schematically illustrated in Scheme 1. The detailed explanation to prepare nanoimprinted AAO template with the conductive layers of $\mathrm{Au}$ and Ni (Step I to IV) can be found in experimental section. Sb nanorod arrays are ${ }_{25}$ achieved by electrodepositing $\mathrm{Sb}$ precursor inside AAO template (Step V) and subsequently dissoluting the AAO template (Step VI). The electrodeposition represents a cost-effective and mature technique to obtain nanoarrays. The structural parameters of the $\mathrm{Sb}$ nanorods can be easily adjusted by changing the experimental 30 parameters of both template fabrication and electrochemical deposition. At last, $\mathrm{Sb}$ nanorod arrays were directly used for assembling sodium cells without use of carbon black and binder, which shall largely avoid undesirable interfaces in the electrode material.

35

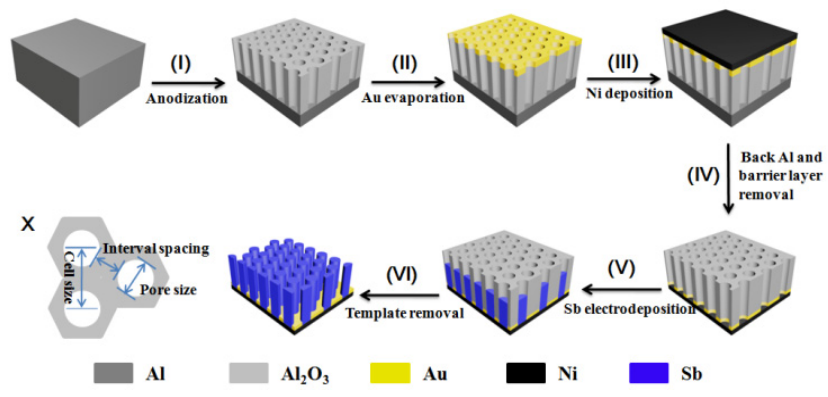

Scheme 1 Schematic illustration of the fabrication processes of $\mathrm{Sb}$ nanorod arrays by using the nanoimprinted AAO templating technique with the assistance of an electrodeposition process. X) ${ }_{40}$ Size schematic of AAO template.

Fig. 1 shows scanning electron microscopy (SEM) images of the nanoimprinted AAO template (Fig. 1a and b), and Sb nanorod arrays (Fig. 1c-f). As displayed in Fig. 1a and b, the hexagonal arranged pores of AAO template are perfectly uniform in large45 area, and the pore size is about $210 \mathrm{~nm}$. It is worth mentioning that both the size and depth of pores can be accurately adjusted to obtain the desired size depending on the time of pore-widening and anodization, respectively. Fig. 1c-f illustrate the top and tilted views of the as-prepared $\mathrm{Sb}$ nanorod arrays which keep the highly 50 ordered and vertically well-aligned growth in large-scale. As is clearly seen from the insets in Fig. 1d and f, Sb nanorods possess the uniform diameter of about $210 \mathrm{~nm}$, and the interval distance among nanorods is as large as $190 \mathrm{~nm}$, as defined by the pore size of as-prepared AAO template. In this work, we used the cell size 55 of nanoimprinted AAO template is $400 \mathrm{~nm}$, and larger cell size $(800 \mathrm{~nm})$ also can be obtained, as shown in Fig. S1. By using that ( $800 \mathrm{~nm}$ AAO template), larger interval spacing should be easily controllable.

Fig. 1g reveals an optical image of Sb nanorod arrays directly ${ }_{60}$ grown on $\mathrm{Au} / \mathrm{Ni}$ substrate. It clearly illustrates that $\mathrm{Sb}$ nanorod arrays with $\mathrm{Au} / \mathrm{Ni}$ substrate can be severely rolled without visible signs of degradation, implying the good adhesion and mechanical robustness of the arrays. This feature might indicate our electrodes for a possible application in flexible electronics. As ${ }_{65}$ shown in Figure $1 \mathrm{~g}$ inset, highly ordered $\mathrm{Sb}$ nanorod arrays are obtained over a large area (around $\mathrm{cm}^{2}$-sized range). Larger areas can also be easily achievable by using the larger-sized $\mathrm{Ni}$ imprinting stamp combined well-established roll to roll process. The X-ray diffraction (XRD) pattern of the as-prepared $\mathrm{Sb}$ 70 nanorod arrays is shown in Fig. S2. Except for the reflections of the substrate (Au and $\mathrm{Ni}$ ), all the other diffraction peaks can be readily indexed to the rhombohedral Sb phase (JCPDS No. 350732) without any impurity, indicating the successful synthesis of Sb. Transmission electron microscopy (TEM) image (Fig. 1h) 75 clearly shows the diameter and length of Sb nanorod are about $210 \mathrm{~nm}$ and $1.5 \mu \mathrm{m}$, respectively. High resolution TEM (HRTEM) image in Fig. 1i exhibits the lattice fringes with the distance of $3.09 \AA$, corresponding to the (012) planes of rhombohedral Sb, further confirming the high crystallinity of the sample. The 80 selected area electron diffraction (SEAD) pattern in Fig. 1i inset proves that the $\mathrm{Sb}$ nanorods are polycrystalline. Successful growth of such highly ordered and vertically well-aligned $\mathrm{Sb}$ nanorod arrays with large interval spacing may offer high ion accessibility, direct electron and ion transport, and robust ${ }_{85}$ electrode integrity. Therefore, a promising electrochemical performance is highly expected.

For electrochemical evaluation, $\mathrm{Sb}$ nanorod arrays were directly used as anodes for $\mathrm{Na}$ coin cells. Fig. 2a shows representative cyclic voltammogram $(\mathrm{CV})$ of the initial ten cycles 90 at a scan rate of $0.5 \mathrm{mV} \mathrm{s}^{-1}$ between 0.01 and $2.0 \mathrm{~V}\left(v s . \mathrm{Na}^{+} / \mathrm{Na}\right)$. In accordance with previous reports, ${ }^{23-28}$ it clearly presents that the first sodiation scan curve is distinctively different with that of the following ones, suggesting an activation process during the first sodiation process. The first sodiation of $\mathrm{Na}$ occurs along one 95 sharp current peak at $0.323 \mathrm{~V}$, together with two obscure current peaks at 0.461 and $0.283 \mathrm{~V}$. However, in the second sodiation scan, four distinct current peaks at $0.614,0.355,0.309$, and 0.130 $\mathrm{V}$ are shown. The peak at $0.130 \mathrm{~V}$ may be induced by the incomplete sodiation of the former steps in the activation ${ }_{100}$ process, ${ }^{26}$ then disappears in the subsequent ones. Other three sodiation peaks are continuously shown, whereas shifting to higher potentials and remaining stable in their shapes and intensities in the following ones, suggesting the occurrence of stable sodiation reactions. ${ }^{29}$ In the first desodiation scan, there are 
one broad peak at $0.835 \mathrm{~V}$ and one sharp peak at $0.977 \mathrm{~V}$, which keep showing in the subsequent scans, while slightly shifting to lower potentials. As a consequence, the voltage difference between sodiation and desodiation process is lessening, reflecting 5 smaller polarization.
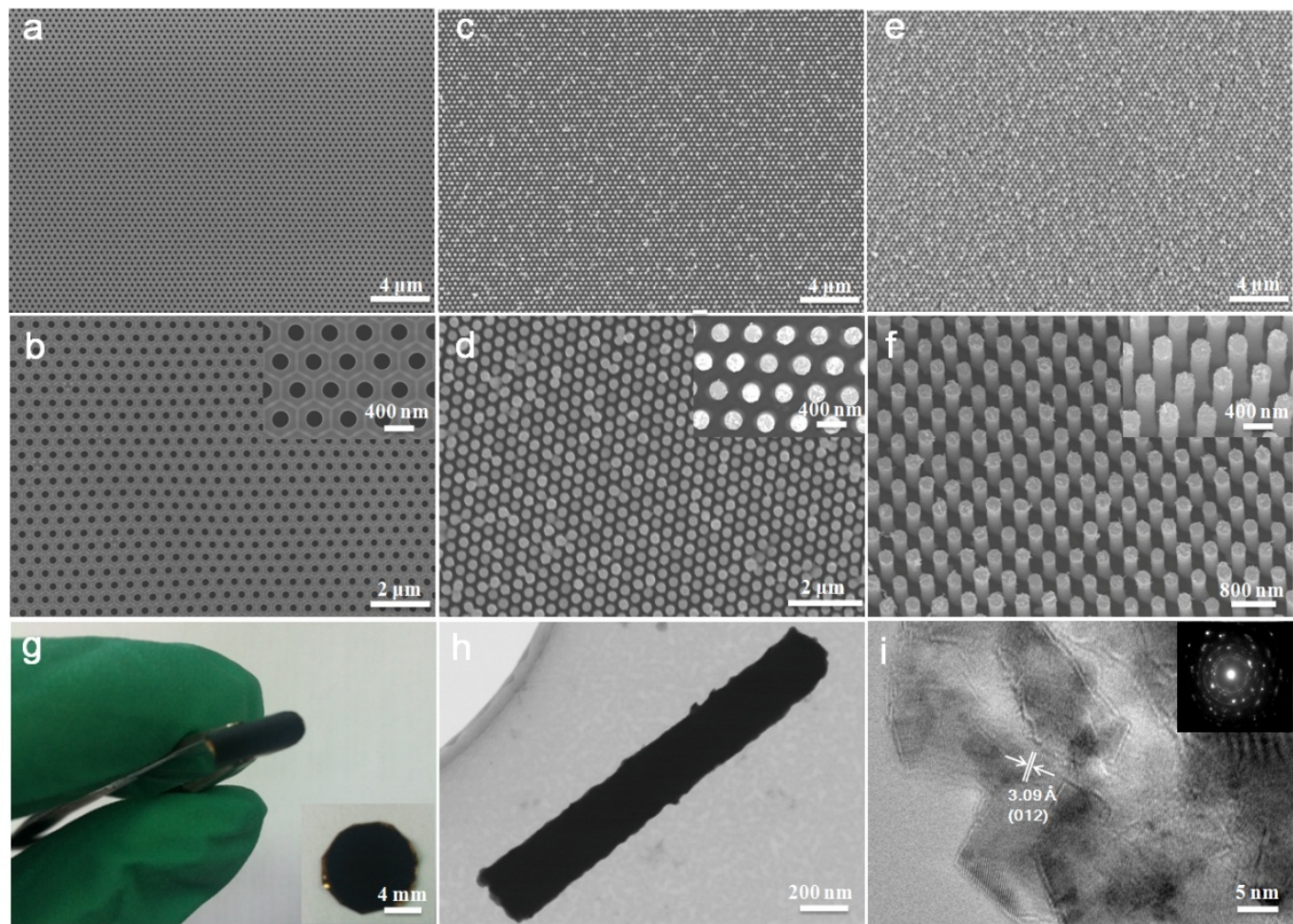

Fig.1 SEM images of nanoimprinted AAO template ( $a, b)$, top view (c, d) and tilted view (e, f) of Sb nanorod arrays. g) Optical image of $\mathrm{Sb}$ nanorod arrays on $\mathrm{Au} / \mathrm{Ni}$ substrate. h) TEM image of a single Sb nanorod. i) HRTEM image of Sb nanorods and SAED pattern (inset).

Galvanostatic charge/discharge curves of $\mathrm{Sb}$ arrays electrode at a current density of $0.5 \mathrm{~A} \mathrm{~g}^{-1}$ are displayed in Fig. 2b, which show typical characteristics of $\mathrm{Sb}$ electrodes. ${ }^{25-28}$ In the first discharge curve, it shows the presence of three sodiation plateaus, 15 which are a short slope at $0.590 \mathrm{~V}$, a long plateau at $0.502 \mathrm{~V}$, and a much shorter one at $0.391 \mathrm{~V}$. These three plateaus constantly show in the following curves, corresponding to the sequence of amorphous $\mathrm{Sb} \rightarrow$ amorphous $\mathrm{Na}_{3} \mathrm{Sb} \rightarrow \mathrm{Na}_{3} \mathrm{Sb}$ (hex)/ $\mathrm{Na}_{3} \mathrm{Sb}$ (cub) $\rightarrow \mathrm{Na}_{3} \mathrm{Sb}$ (hex). ${ }^{25-28}$ In the first charge curve and the subsequent 20 ones, two pronounced disodiation plateaus are constantly shown, which are a long plateau at $0.800 \mathrm{~V}$ and another short one at $0.898 \mathrm{~V}$, corresponding to the process of $\mathrm{Na}_{3} \mathrm{Sb}$ (hex) $\rightarrow$ amorphous $\mathrm{Sb}$ transition and partial crystallization of $\mathrm{Sb}$, respectively. ${ }^{25-28}$ All of these voltage profiles are in good

25 agreement with the CV results in Fig. 2a. Furthermore, it is worthwhile to be emphasized that the voltage profiles of both sodiation and desodiation are perfectly reproducible from cycles 1 to 100 , indicating the stable structure of Sb nanorod arrays and excellent electrochemical reversibility during cycling.

30 As shown in Fig. 2c, Sb nanorod arrays anode demonstrated excellent cycling performance. At a current density of $0.2 \mathrm{~A} \mathrm{~g}^{-1}$, it delivered a high capacity of $620 \mathrm{mAh} \mathrm{g}^{-1}$ at the 100th cycle, and $521 \mathrm{mAh} \mathrm{g}^{-1}$ at the 250 th cycle with a capacity retention of $84 \%$. The cycling performance is comparable to those reported results ${ }_{35}$ regarding Sb-based anodes (Table S1). The capacity decay of Sb nanorod arrays was attributed to inevitable increasing thick SEI film and huge volume changes of $\mathrm{Sb}$ anode upon cycling, as shown in Fig. S3. The decay can also be accordingly reflected on charge/discharge profiles in different cycles (Fig. S4). It is 40 worthwhile noting that the cycling performance of this anode was obtained without any sophisticated chemical modification of $\mathrm{Sb}$ material. It is reported that the protective coating by carbon or other materials can effectively tolerate the massive volume changes and alleviate the stress strain during the $\mathrm{Na}$ ${ }_{45}$ alloying/dealloying reaction. ${ }^{19,23,24,30}$ Therefore, we deduce that such strategy could be the direction of further improvement on cycling performace. The areal capacity of $\mathrm{Sb}$ nanorod arrays is also calculated, which is about $215 \mu \mathrm{Ah} \mathrm{cm}^{-2}$ at a current density of $80 \mu \mathrm{A} \mathrm{cm}^{-2}$. The Coulombic Efficiency (CE) for the first cycle 50 is around $78.2 \%$, while it stabilizes at around $97.8 \%$ for the following cycles, indicating facile and efficient ions and electrons transport in this electrode. ${ }^{31-33}$ When cycled at a large current density of $0.5 \mathrm{~A} \mathrm{~g} \mathrm{~g}^{-1}, \mathrm{Sb}$ nanorod arrays showed almost the same capacity with that at $0.2 \mathrm{~A} \mathrm{~g}^{-1}$, but shorter cycle life due to more 55 serious morphology changes. 

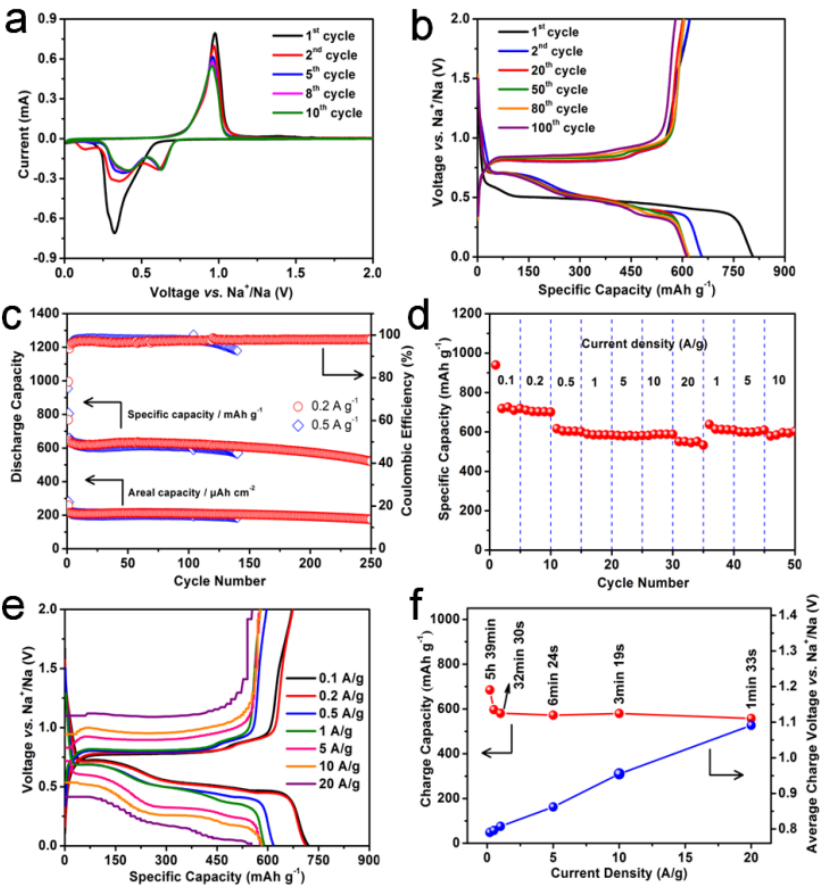

Fig.2 Electrochemical performance of Sb nanorod arrays anode. a) Cyclic voltammetry at a scan rate of $0.5 \mathrm{mV} \mathrm{s}^{-1}$ between 0.01 to $2.0 \mathrm{~V}\left(v s . \mathrm{Na}^{+} / \mathrm{Na}\right)$. b) Galvanostatic charge/discharge voltage 5 profiles in different cycles at a current density of $0.5 \mathrm{~A} \mathrm{~g} \mathrm{~g}^{-1}$. c) Cycling performance at current densities of $0.2\left(80 \mu \mathrm{A} \mathrm{cm}^{-2}\right)$ and $0.5 \mathrm{~A} \mathrm{~g}^{-1}\left(32 \mu \mathrm{A} \mathrm{cm}^{-2}\right)$. d) Rate performance and e) corresponding charge/discharge voltage profiles at various current densities from 0.1 to $20 \mathrm{~A} \mathrm{~g} \mathrm{~g}^{-1}$. f) Respective charge capacity and average 10 charge working potential at various current densities.

In addition to the high capacity and cyclability, Sb nanorod arrays anode also displays remarkably high rate capability. Fig. $2 \mathrm{~d}$ demonstrates the rate performance investigated at various current densities from 0.1 to $20 \mathrm{~A} \mathrm{~g}^{-1}$. It is striking to note that $\mathrm{Sb}$ 15 nanorod arrays electrode still can be reversibly cycled at super high current densities of 10 and $20 \mathrm{~A} \mathrm{~g} \mathrm{~g}^{-1}$ and deliver large capacities of 579.7 and $557.7 \mathrm{mAh} \mathrm{g}^{-1}$, respectively, indicating the fast transfer of $\mathrm{Na}$ ions and electrons through $\mathrm{Sb}$ nanorod arrays. When the current densities are reset to 1,5 , and $10 \mathrm{~A} \mathrm{~g}^{-1}$, 20 the capacities fully recovered and are even slightly higher than those of the first set at the same current densities, implying that the unique electrode structure can preserve the integrity of the electrode and accommodate huge change of current density, which is highly crucial for high power applications of 25 rechargeable batteries. As far as we know, this is the best rate capability in comparison with the previously reported Sb-based anodes in SIBs, as shown in Table 1. The corresponding voltage profiles of the electrode at various current densities are presented in Fig. 2e. As current density increasing from 0.1 to $20 \mathrm{~A} \mathrm{~g} \mathrm{~g}^{-1}$, the

30 charge/discharge voltage profiles have similar shapes, with minimal increase of the voltage offset, even at ultra-high current density of $20 \mathrm{~A} \mathrm{~g}^{-1}$, suggesting facile electron transport and small mechanical energy loss of the electrode. Moreover, when the current density is reduced back to $1 \mathrm{~A} \mathrm{~g}^{-1}$ (Fig. S5), the voltage 35 profiles recovered and are perfectly reproducible in comparison with that of the first set at the same current density $\left(1 \mathrm{~A} \mathrm{~g} \mathrm{~g}^{-1}\right)$, reflecting the stable structure of $\mathrm{Sb}$ nanorod arrays to strongly tolerate the repeated and rapid $\mathrm{Na}$ alloying/delloying reactions. Charge working potentials of the electrode at different current 40 densities are shown in Fig. 2f. The potentials only display a small increase of $0.027 \mathrm{~V}$ when the current is raised from 0.1 to $1 \mathrm{~A} \mathrm{~g}^{-1}$, and an increase of 200 times of the current brings an increase of the potential of only $0.311 \mathrm{~V}$ when the current is raised to $20 \mathrm{~A} \mathrm{~g}^{-}$ ${ }^{1}$, indicating the excellent structure stability of $\mathrm{Sb}$ nanorod arrays 45 and fast electron transport. In addition, the charging time are 6 $\min 24 \mathrm{~s}, 3 \min 19 \mathrm{~s}$, and $1 \min 33 \mathrm{~s}$ at the current densities of 5 , 10 , and $20 \mathrm{~A} \mathrm{~g}^{-1}$, with high charge capacities of 572.4, 579.7, and $557.7 \mathrm{mAh} \mathrm{g}^{-1}$, respectively. The electrodes can be charged and discharged at such high rates with such high capacities in such 50 short time, which are highly desired for high power and energy devices.

As clearly illustrated in the above results, highly ordered $\mathrm{Sb}$ nanorod arrays anode shows extremely large capacities, excellent cycle stability, and superior rate capability for Na-ion storage, 55 which can be ascribed to its pathbreaking electrode design on the basis of the following factors. First, the nanoscaled diameter of $\mathrm{Sb}$ nanorods can shorten $\mathrm{Na}$ ion diffusion pathway compared to the bulk Sb powders. Nanostructuring of the active materials can also moderate the effect of volume changes and enhance kinetics 60 of the conversion and alloying reactions. ${ }^{38-40}$ Second, Sb nanorod arrays themselves as electric conductors directly connect to the conductive $\mathrm{Au} / \mathrm{Ni}$ substrate offering fast and accessible electron transport, giving rise to superior rate capability. Third, Sb nanorod arrays show well vertical alignment and uniform large ${ }_{65}$ interval spacing (about $190 \mathrm{~nm}$ ), which provide direct channels for electrolyte and ions to permeate into all the portions of arrays, and thus $\mathrm{Na}$ ions can fully contact $\mathrm{Sb}$ nanorods without any dead angels, improving $\mathrm{Na}$ ion accessibility. This point surpasses the traditional materials including powder-based materials and 70 disordered network that charge carriers must move through the interstitial regions or spaces within materials to access the internal part. Owing to this feature as well as the large surface area of $\mathrm{Sb}$ nanorod arrays, large capacities at high rates are obtained. Moreover, the large interval spacing in arrays can 75 prevent the pulverization by facile strain relaxation during cycling. The third point is extremely significant to ensure $\mathrm{Sb}$ nanorod arrays to show high capacities, long-term cycling stability, and excellent rate capability. In order to better reveal the advantages of highly ordered arrays with large interval spacing, 80 we conducted parallel comparative tests between vertically wellaligned $\mathrm{Sb}$ nanorod arrays ( $\mathrm{S}-\mathrm{Sb} \mathrm{NRs}$ ) and attached $\mathrm{Sb}$ nanorod arrays (A-Sb NRs) with very limited interval spacing for the permeation of electrolyte (relating to $\mathrm{Na}$ ion transport and strain release) on the electrochemical performance. These two arrays 85 have the same length of $1.5 \mu \mathrm{m}$, and more detailed structure parameters of A-Sb NRs can be found in Table S2. 
Table 1. Electrochemical performance comparison of the as-prepared Sb nanorod arrays with previously reported Sb-based anodes.

\begin{tabular}{|c|c|c|c|c|c|c|}
\hline \multirow{2}{*}{ Materials } & \multirow{2}{*}{$\begin{array}{l}\text { Current } \\
\text { density, } \mathrm{A} \mathrm{g}^{-1}\end{array}$} & \multicolumn{3}{|c|}{ Cycling Capacity, $\mathrm{mAh} \mathrm{g}^{-1}$} & \multirow{2}{*}{\multicolumn{2}{|c|}{$\begin{array}{l}\text { Rate Capability, } \mathrm{mAh} \mathrm{g}^{-1} \\
\text { (current density, } \mathrm{A} \mathrm{g}^{-1} \text { ) }\end{array}$}} \\
\hline & & $2^{\text {nd }}$ & $50^{\text {th }}$ & $100^{\text {th }}$ & & \\
\hline Nanocomposite $\mathrm{Sb} / \mathrm{C}^{19}$ & 0.1 & 610 & 570 & 575 & $489(1)$ & $309(2)$ \\
\hline $\mathrm{SnSb} / \mathrm{C}$ nanocomposite ${ }^{23}$ & 0.1 & $\sim 540$ & 435 & / & $433(0.2)$ & $274(1)$ \\
\hline $\mathrm{Sb} / \mathrm{C}$ fibers ${ }^{24}$ & 0.1 & $\sim 425$ & $\sim 420$ & 400 & $300(1)$ & $104(6)$ \\
\hline Monodisperse Sb Nanocrystals ${ }^{25}$ & 0.66 & $\sim 590$ & $\sim 560$ & $\sim 580$ & $\sim 550(5.28)$ & $\sim 520(13.2)$ \\
\hline Bulk Sb ${ }^{26}$ & 0.33 & $\sim 540$ & $\sim 560$ & $\sim 570$ & $506(1.32)$ & $491(2.64)$ \\
\hline $\mathrm{Sb} / \mathrm{MWCNT}$ nanocomposite ${ }^{27}$ & 0.2 & $\sim 510$ & $\sim 450$ & $\sim 400$ & $350(1)$ & $225(2)$ \\
\hline $\mathrm{Sb}$ porous hollow microspheres ${ }^{28}$ & 0.66 & 574.9 & $\sim 520$ & 502.3 & $470.3(1.6)$ & $312.9(3.2)$ \\
\hline SnSb-porous carbon nanofibers ${ }^{29}$ & 0.1 & 349 & 350 & 350 & $198(5)$ & $113(10)$ \\
\hline Sb-C nanofibers ${ }^{34}$ & 0.2 & $\sim 495$ & $\sim 500$ & $\sim 490$ & $382(1.8)$ & $337(3)$ \\
\hline Porous $\mathrm{Sb} / \mathrm{Cu}_{2} \mathrm{Sb}$ anode ${ }^{35}$ & 0.066 & $\sim 660$ & $\sim 550$ & $\sim 480$ & $\sim 470(0.66)$ & $\sim 170(3.3)$ \\
\hline Rod-like Sb-C composite ${ }^{36}$ & 0.05 & $\sim 650$ & $\sim 440$ & $\sim 431$ & $\sim 500(0.05)$ & $\sim 259(0.25)$ \\
\hline Sn-Ge-Sb alloys ${ }^{37}$ & 0.085 & 833 & 662 & I & $\sim 420(4.25)$ & $381(8.5)$ \\
\hline $\mathrm{Sb}$ nanorod arrays (this work) & 0.5 & 655.7 & 618.4 & 612.6 & $579.7(10)$ & $557.7(20)$ \\
\hline
\end{tabular}

Fig. 3 demonstrates the different $\mathrm{Na}$ ion transport modes in 5 these two arrays, noting that metal $\mathrm{Sb}$ is a good electric conductor and it can effectively transfer electrons between conductive substrate and nanorods without the help of conductive additive carbon. As shown in Fig. 3a and b, due to the large interval spacing in vertical well-aligned arrays, $\mathrm{Na}$ ions can easily diffuse 10 into the matrix in $\mathrm{S}-\mathrm{Sb} \mathrm{NRs}$, resulting to superior $\mathrm{Na}$ ion accessibility, thus large capacities are highly expected, especially at high current densities. In contrast, SEM image (Fig. 3c) of A$\mathrm{Sb}$ NRs displays severe agglomerated nanorods and attendant very limited interval spacing in arrays. Therefore, the electrolyte 15 is very difficult to directly penetrate into the bottom region of A$\mathrm{Sb}$ NRs through the top of attached nanorods (Fig. 3d). As a substitute, $\mathrm{Na}$ ions have to diffuse through interstitial regions within arrays, which would lead to incomplete active sites for $\mathrm{Na}^{+}$, then showing decreased capacities of A-Sb NRs. On the other 20 hand, the large interval spacing in S-Sb NRs can provide a facile strain relaxation during cycling, thereby preventing the pulverization. However, for A-Sb NRs, the joint parts tend to break since the stress existed among these entangled $\mathrm{Sb}$ nanorods, leading to poor transport of electrons and ions, thereby rapid 25 capacity decay. ${ }^{41,42}$

Based on the above analysis of different $\mathrm{Na}$ ion transport and strain release modes, we investigated the electrochemical performance of A-Sb NRs and S-Sb NRs under the same testing conditions. As shown in Fig. 4a, the A-Sb NRs have the similar ${ }_{30} \mathrm{CV}$ curves with $\mathrm{S}-\mathrm{Sb}$ NRs (Fig. 2a), indicating the identical sodiation/desodiation mechanism. However, the capacities and cycling stability are far less than those of S-Sb NRs. In Fig. 4b, A-Sb NRs show a first discharge capacity of $529.5 \mathrm{mAh} \mathrm{g}^{-1}$ and $\mathrm{CE}$ of $79.5 \%$ at a current density of $1 \mathrm{~A} \mathrm{~g}^{-1}$. In the following 50 35 cycles, A-Sb NRs keep stable discharge capacity of around 475 $\mathrm{mAh} \mathrm{g}^{-1}$, however, the CE gradually decreases, implying the irreversible reactions occurred during this period. From the 50th cycle, A-Sb NRs undergo rapid capacity decay, delivering only $345.1 \mathrm{mAh} \mathrm{g}^{-1}$ in the 60th cycle. The galvanostatic 40 charge/discharge voltage profiles of A-Sb NRs (Fig. S6) further reveal this decay phenomenon from another point of view. In the 50th cycle, the discharge plateau appears a big decrease from $0.37 \mathrm{~V}$ in 10 th cycle to $0.17 \mathrm{~V}$ and the flat charge plateau at 0.87 is replaced by a big slope. In contrast, an excellent cycling ${ }_{45}$ stability of $\mathrm{S}-\mathrm{Sb}$ NRs is observed at the same current density and the electrode still can retain a constant and even slightly ahead of capacity of $625.2 \mathrm{mAh} \mathrm{g}^{-1}$ over 60 cycles and high CE of around $98 \%$ (except the first cycle of $83 \%$ ) (Fig. 4c). Furthermore, the voltage profiles of $\mathrm{S}-\mathrm{Sb}$ NRs (Fig. S7) present perfect 50 reproducibility during 50 cycles. Notably, it is as expected that the capacity, CE, and cycling stability of S-Sb NRs are much better than those of A-Sb NRs, which is largely ascribed to more efficient ion transport, as well as more facile strain release in SSb NRs.
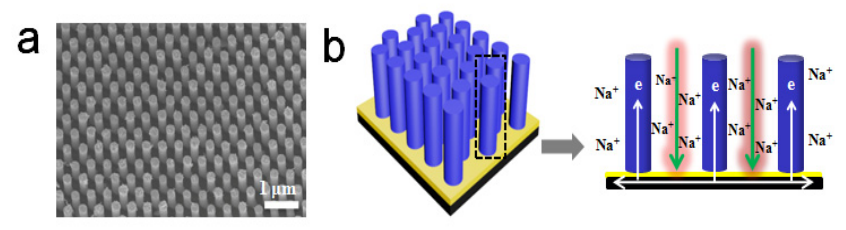

C
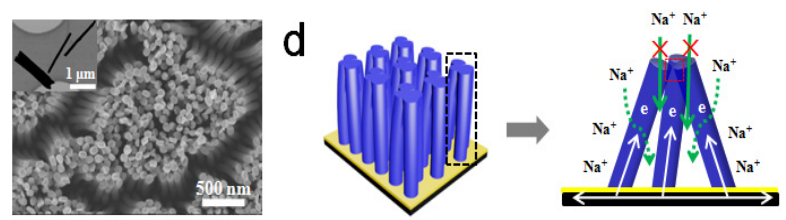

Fig. 3 SEM images of a) S-Sb NRs and c) A-Sb NRs (Inset: TEM image of A-Sb NRs). Corresponding schematic illustration of transport mechanism of $\mathrm{Na}$ ions and electrons in b) $\mathrm{S}-\mathrm{Sb}$ NRs and d) A-Sb NRs.

60 Nyquist plots of A-Sb NRs and S-Sb NRs are displayed in Fig. $4 \mathrm{~d}$ and e to investigate their resistance change with the increased cycles. From the first cycle to 50th cycle, A-Sb NRs show a gradually increased resistance (Fig. 4d). However, for S-Sb NRs, 
the change of resistance is negligible (Fig. 4e), further confirming relatively easier $\mathrm{Na}$ ion transport in $\mathrm{S}-\mathrm{Sb} \mathrm{NRs}$, thereby reducing the irreversible capacity loss and enhancing cycling performance. For the rate performance of A-Sb NRs electrode (Fig. 4f), it 5 demonstrates the similar trend with $\mathrm{S}-\mathrm{Sb} \mathrm{NRs}$ in the first 45 cycles but with lower capacities. In addition, from the 46th cycle (a current density of $10 \mathrm{~A} \mathrm{~g}^{-1}$ in the second rate set), the capacities rapidly decrease. Under high current densities, the electrode needs to finish the charge and discharge processes in a 10 very short time. Therefore, high ions accessibility, good electrical conductivity, and stable electrode structure are essential. A-Sb NRs electrode shows limited ions accessibility, and the attached structure of is not conducive to release strain induced by volume expansion, resulting in unstable electrode structure. As a sum 15 result, under the high current density of $10 \mathrm{~A} \mathrm{~g}^{-1}$ in the second rate set, A-Sb NRs electrode displays rapid capacity decay. The largely different electrochemical performance between A-Sb NRs and S-Sb NRs fully supports our assumption of the predominance of this highly ordered alignment with large interval spacing 20 electrode design for Na-ion storage. To more comprehensively reveal the importance of highly ordered arrays with interval spacing, we also compared the electrochemical performance of another two kinds of arrays, as shown in Table S2 and Fig. S8.
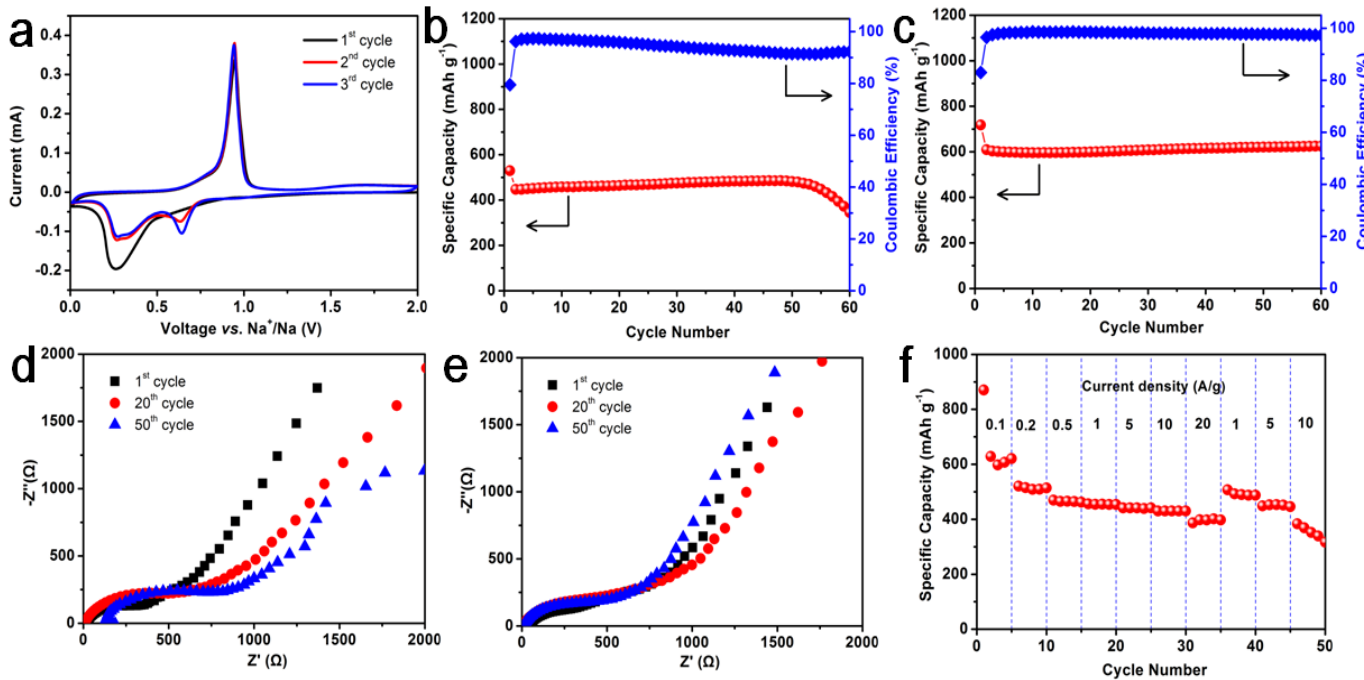

Fig. 4 a) Cyclic voltammetry of A-Sb NRs electrode at a scan rate of $0.5 \mathrm{mV} \mathrm{s}{ }^{-1}$ between 0.01 to $2.0 \mathrm{~V}\left(v s\right.$. $\left.\mathrm{Na}^{+} / \mathrm{Na}\right)$. Cycling performance of b) A-Sb NRs and c) S-Sb NRs at a current density of $1 \mathrm{~A} \mathrm{~g}^{-1}$. Nyquist plots of d) A-Sb NRs and e) S-Sb NRs at discharge state $(0.01 \mathrm{~V})$ from $1 \mathrm{MHz}$ to $10 \mathrm{mHz}$. f) Rate performance of A-Sb NRs electrode at various current densities from 0.1 to $20 \mathrm{~A} \mathrm{~g}{ }^{-1}$.

30 In addition, the remarkable electrode integrity is also largely beneficial for the excellent electrochemical performance. The good adhesion between $\mathrm{Sb}$ nanorod arrays and conductive substrate can ensure the robust arrays integrity to accommodate volume expansion/contraction upon cycling, resulting in good

35 cycling and rate performance. To better verify this point, the morphology of $\mathrm{Sb}$ nanorod arrays after long-term cycling was also investigated. Fig. 5 shows SEM and TEM images of $\mathrm{Sb}$ nanorod arrays cycled at a current density of $10 \mathrm{~A} \mathrm{~g}^{-1}$ after 70 cycles in fully desodiation state. As can be seen from the top (Fig. 40 5a) and side view (Fig. 5b), Sb nanorod arrays still maintain their highly ordered and vertically well-aligned feature with clear interval spacing after long-term cycling at such high current density, which prevents pulverization and preserves electrode integrity, giving rise to excellent cycling and rate performance.

${ }_{45} \mathrm{We}$ scratched $\mathrm{Sb}$ nanorods off the substrate and observed the uniform and well-preserved Sb nanorods on TEM (Fig. 5b inset) image. The diameter and length of the cycled $\mathrm{Sb}$ nanorod are around $300 \mathrm{~nm}$ and $2.1 \mu \mathrm{m}$, respectively, and larger than those of the pristine $\mathrm{Sb}$ nanorod (Fig. 1h) with rough surfaces, deriving 50 from the volume expansion/contraction in repeated sodiation/desodiation processes. Despite the volume change, there is no structural collapse and agglomeration of $\mathrm{Sb}$ nanorod arrays, suggesting the chemical and mechanical robustness of the arrays electrode. Based on the above four major advantages of the 55 electrode structure, $\mathrm{Sb}$ nanorod arrays anode showed the overall excellent electrochemical performance for $\mathrm{Na}$-ion storage.

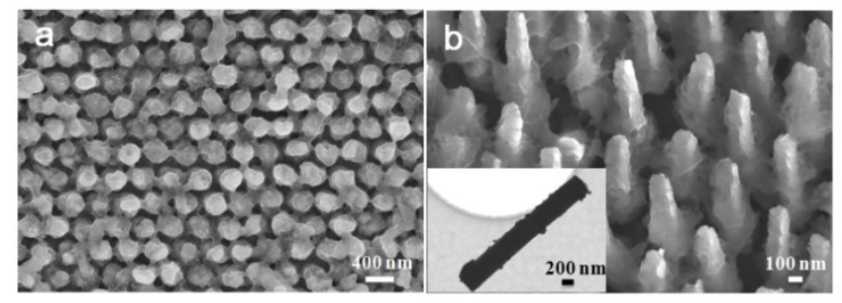

Fig. 5 SEM images of a) top view and b) tilted view of $\mathrm{Sb}$ nanorod arrays electrode after 70 cycles at a current density of 10 ${ }_{60} \mathrm{~A} \mathrm{~g}^{-1}$. (Inset: TEM image of a single $\mathrm{Sb}$ nanorod.)

To display the feasibility of $\mathrm{Sb}$ nanorod arrays in full-cell configuration, a full cell coupled by $\mathrm{P} 2-\mathrm{Na}_{2 / 3} \mathrm{Ni}_{1 / 3} \mathrm{Mn}_{2 / 3} \mathrm{O}_{2}$ cathode and $\mathrm{Sb}$ nanorod arrays anode was investigated. The structure and electrochemical performance characterizations of P2${ }_{65} \mathrm{Na}_{2 / 3} \mathrm{Ni}_{1 / 3} \mathrm{Mn}_{2 / 3} \mathrm{O}_{2}$ can be seen in Fig. S9 and Fig. S10. This full cell was tested with a voltage range of 1.4-4.0 $\mathrm{V}$ at a large current density of $0.5 \mathrm{~A} \mathrm{~g}^{-1}$ (with respect to the anode weight) using 1.0 $\mathrm{M} \mathrm{NaClO}_{4}$ in EC-PC-5\% FEC electrolyte. According to the 
average working potentials of 3.6 and $0.7 \mathrm{~V} v s . \mathrm{Na}^{+} / \mathrm{Na}$ for P2$\mathrm{Na}_{2 / 3} \mathrm{Ni}_{1 / 3} \mathrm{Mn}_{2 / 3} \mathrm{O}_{2}$ cathode (Fig. S10b) and $\mathrm{Sb}$ nanorod arrays anode (Fig. 2b), respectively, it is reasonably deduced that the full cell operates at around $2.9 \mathrm{~V}$, as indeed shown by Fig. R6a ${ }_{5}$ reflecting charge/discharge profiles of the full cell. Fig. R6b shows the cycling performance of this full cell, in which it delivered a superior capacity retention of around $94 \%$ before 110 cycles with a capacity of around $620 \mathrm{mAh} \mathrm{g}^{-1}$ (relative to $\mathrm{Sb}$ anode weight), which is very close to the theoretical capacity of ${ }_{10} \mathrm{Sb}\left(660 \mathrm{mAh} \mathrm{g}^{-1}\right)$. From the 110th cycle to the 130th cycle, this cell showed a capacity decay to $450 \mathrm{mAh} \mathrm{g}^{-1}$. This decay characteristic is similar with $\mathrm{Na} / \mathrm{Sb}$ half cell, due to the inevitable morphology change of Sb (Fig. S3). Nevertheless, at such a high current density of $0.5 \mathrm{~A} \mathrm{~g} \mathrm{~g}^{-1}$, this cell still can work with a high 15 capacity of about $334 \mathrm{mAh} \mathrm{g}^{-1}$ up to 250 cycles and extremely stable CE of around 98\%. Although the capacity of the 250th cycle is only $54 \%$ the 110 th capacity, the value of $334 \mathrm{mAh} \mathrm{g}^{-1}$ is very attractive considering at such large current density of $0.5 \mathrm{~A}$ $\mathrm{g}^{-1}$. Moreover, according to the above studies, the cycling 20 stability of this full cell might be better at a lower current density.
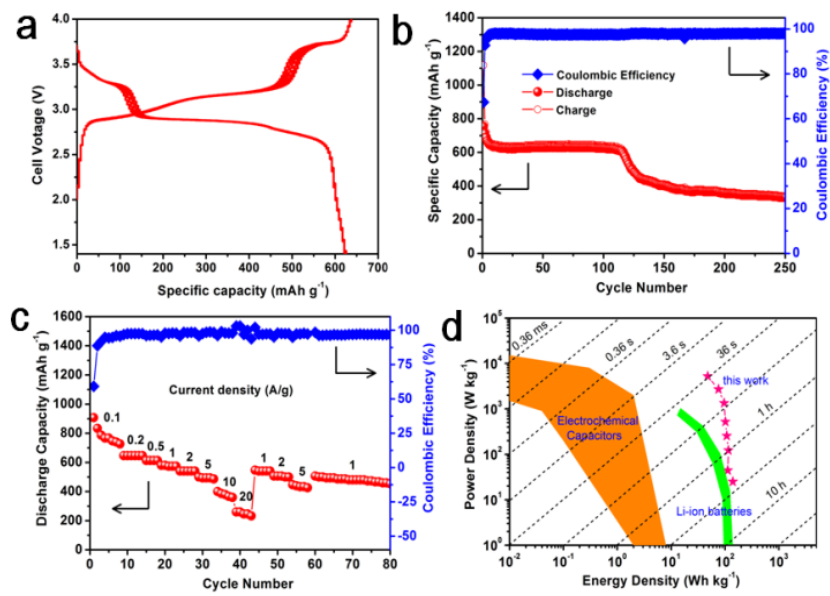

Fig. 6 Electrochemical performance of a full cell coupled by P2$\mathrm{Na}_{2 / 3} \mathrm{Ni}_{1 / 3} \mathrm{Mn}_{2 / 3} \mathrm{O}_{2}$ cathode and $\mathrm{Sb}$ nanorod arrays anode. a) Galvanostatic charge/discharge voltage profiles of five cycles, 25 and b) Cycling performance at a current density of $0.5 \mathrm{~A} \mathrm{~g}^{-1}$ (relative to the anode weight). c) Rate Capability (with respect to the anode weight), and d) Ragone plot of energy and power density (with respect to the total mass of anode and cathode) at various current densities from 0.1 to $20 \mathrm{~A} \mathrm{~g}^{-1}$. The shaded curves 30 were obtained from ref. 42 .

Notably, this full cell also displayed high rate capability, as shown in Fig. R6c. Benefiting from the great rate capability of the $\mathrm{Na} / \mathrm{Sb}$ half cell, it can be cycled at very large current densities of 10 and $20 \mathrm{~A} \mathrm{~g} \mathrm{~g}^{-1}$, and maintained stable reversibility. In 35 addition, these capacities can be fully recovered when the cell went back to the low current densities. The energy density and power density of the full cell were further evaluated with a Ragone plot, which were calculated based on the total mass of the cathode and anode active materisals, as shown in Fig. R6d. These 40 values show a clear comparison with commercial lithim-ion batteries and electochemical capacitors. Such cell could provide much higher power densities than commercial Li-ion batteries, while the energy densities are several times bigger than that of electrochemical capacitors. These capabilities suggest that Sb 45 nanorod arrays anodes can be used to build large energy storage and conversion devices with both high-power and high-energy densities.

\section{Conclusions}

In summary, we presented a large-scale highly ordered $\mathrm{Sb}$ 50 nanorod arrays with uniform large interval spacing. Used as SIBs anode, $\mathrm{Sb}$ nanorod arrays delivered a high capacity retention of $84 \%$ up to 250 cycles. Remarkably, the anode showed superior rate capability with high capacities of 579.7 and $557.7 \mathrm{mAh} \mathrm{g}^{-1}$ at 10 and $20 \mathrm{~A} \mathrm{~g}^{-1}$, respectively, and fully recovered the low rate 55 capacities. The excellent electrochemical performance is achieved in return for its pathbreaking electrode design which ensures high $\mathrm{Na}$ ion accessibility, fast electron transport, and strong structural integrity. Moreover, the successful application of such full cell indicates that $\mathrm{Sb}$ nanorod arrays anodes can be used to build large 60 energy storage and conversion devices with both high-power and high-energy densities.

\section{Acknowledgments}

The authors acknowledge the financial support from European Research Council (ThreeDsurface: 240144), BMBF (ZIK65 3DNanoDevice: 03Z1MN11), BMBF (Meta-ZIKBioLithoMorphie: 03Z1M511), Volkswagen-Stiftung (Herstellung funktionaler Oberflächen: I/83 984).

\section{Notes and references}

Institute for Physics and IMN MacroNano ${ }^{\circledR}$, Technical University of 70 Ilmenau, Ilmenau 98693, Germany. Fax: +49(0)3677 69-3746; Tel: +49(0)3677 69-3748; E-mail: yong.lei@tu-ilmenau.de

†Electronic Supplementary Information (ESI) available: See DOI: $10.1039 / \mathrm{b} 000000 \mathrm{x} /$

1. V. Palomares, P. Serras, I. Villaluenga, K. B. Hueso, J. CarreteroGonzalez and T. Rojo, Energy Environ. Sci., 2012, 5, 5884-5901.

2. S. W. Kim, D. H. Seo, X. H. Ma, G. Ceder and K. Kang, Adv. Energy Mater., 2012, 2, 710-721.

80 3. S. Y. Hong, Y. Kim, Y. Park, A. Choi, N. S. Choi and K. T. Lee, Energy Environ. Sci., 2013, 6, 2067-2081.

4. M. D. Slater, D. Kim, E. Lee and C. S. Johnson, Adv. Funct. Mater., 2013, 23, 947-958.

5. G. Che, B. B. Lakshmi, E. R. Fisher and C. R. Martin, Nature, 1998, 393, 346-349.

6. Y. Li, B. Tan and Y. Wu, Nano Lett., 2008, 8, 265-270.

7. P. L. Taberna, S. Mitra, P. Poizot, P. Simon and J. M. Tarascon, Nat. Mater., 2006, 5, 567-573.

8. Z. L. Wang and J. H. Song, Science, 2006, 312, 242-246.

90 9. A. L. M. Reddy, M. M. Shaijumon, S. R. Gowda and P. M. Ajayan, Nano Lett., 2009, 9, 1002-1006.

10. J. Jiang, Y. Li, J. Liu and X. Huang, Nanoscale 2011, 3, 45-48.

11. Y. Liu, Y. Xu, Y. Zhu, J. N. Culver, C. A. Lundgren, K. Xu and C. Wang, ACS Nano., 2013, 7, 3627-3634.

95 12. J. Liu Y. Li, X. Huang, R. Ding, Y. Hu, J. Jiang and L. Liao, J. Mater. Chem., 2009, 19, 1859-1864.

13. L. Wen, Y. Mi, C. Wang, Y. Fang, F. Grote, H. Zhao, M. Zhou and Y. Lei, Small, 2014, 10, 3162-3168.

14. H. Zhao, C. Wang, R. Vellacheri, M. Zhou, Y. Xu, Q. Fu, M. Wu, F. Grote and Y. Lei, Adv. Mater., 2014, 26, 7654-7659.

15. Z. Zhan AND Y. Lei, ACS Nano, 2014, 8, 3862-3868. 
16. Y. Xu, M. Zhou, L. Wen, C. Wang, H. Zhao, Y. Mi, L. Liang, Q. Fu, M. Wu and Y. Lei, Chem. Mater., 2015, 27, 4274-4280.

17. G. Jeong, Y.-U. Kim, H. Kim, Y.-J. Kim and H.-J. Sohn, Energy Environ. Sci., 2011, 4, 1986-2002.

5 18. V. L. Chevrier and G. Ceder, J. Electrochem. Soc., 2011, 158, A1011-A1014.

19. J. Qian, Y. Chen, L. Wu, Y. Cao, X. Ai and H. Yang, Chem. Commun., 2012, 48, 7070-7072.

20. Y. Wen, B. Wang, G. Zeng, K. Nogita, D. Yeand L. Wang, Chem Asian. J., 2015, 10, 661-666.

21. D. H. Lee, J. Xuand Y. S. Meng, Phys. Chem. Chem. Phys., 2013, 15, 3304-3312.

22. Z. Lu and J. R. Dahn, J. Electrochem. Soc., 2001, 148, A1225A1229.

15 23. L. Xiao, Y. Cao, J. Xiao, W. Wang, L. Kovarik, Z. Nie and J. Liu, Chem. Commun., 2012, 48, 3321-3323.

24. Y. Zhu, X. Han, Y. Xu, Y. Liu, S. Zheng, K. Xu, L. Hu and C. Wang, ACS Nano, 2013, 7, 6378-6386.

25. M. He, K. Kravchyk, M. Walter and M. V. Kovalenko, Nano Lett., 2014, 14, 1255-1262.

26. A. Darwiche, C. Marino, M. T. Sougrati, B. Fraisse, L. Stievano and L. Monconduit, J. Am. Chem. Soc., 2012, 134, 20805-20811.

27. X. Zhou, Z. Dai, J. Bao and Y. G. Guo, J. Mater. Chem. A, 2013, 1, 13727-13731.

25 28. H. Hou, M. Jing, Y. Yang, Y. Zhang, Y. Zhu, W. Song, X. Yang and X. Ji, J. Mater. Chem. A, 2015, 3, 2971-2977.

29. L. Ji, M. Gu, Y. Shao, X. Li, M. H. Engelhard, B. W. Arey, W. Wang, Z. Nie, J. Xiao, C. Wang, J. G. Zhang and J. Liu, Adv. Mater, 2014 , 26, 2901-2908.

30 30. X. Han, Y. Liu, Z. Jia, Y.-C. Chen, J. Wan, N. Weadock, K. J. Gaskell, T. Li and L. Hu, Nano Lett., 2014, 14, 139-147.

31. B. Luo, B. Wang, X. L. Li, Y. Y. Jia, M. H. Liang and L. J. Zhi, $A d v$. Mater., 2012, 24, 3538-3543.

32. C. He, S. Wu, N. Zhao, C. Shi, E. Liu and J. Li, ACS Nano, 2013, 7, 4459-4469.

33. X. L. Jia, Z. Chen, X. Cui, Y. T. Peng, X. L. Wang, G. Wang, F. Wei and Y. F. Lu, ACS Nano, 2012, 6, 9911-9919.

34. L. Wu, X. Hu, J. Qian, F. Pei, F. Wu, R. Mao, X. Ai, H. Yang and Y. Cao, Energy Environ. Sci., 2013, 7, 323-328.

40 35. D. H. Nam, K. S. Hong, S. J. Lim and H. S. Kwon, J. Power Sources, 2014, 247, 423-427.

36. L. Fan, J. Zhang, J. Cui, Y. Zhu, J. Liang, L. Wang and Y. Qian, J. Mater. Chem. A, 2013, 3, 3276-3280.

37. B. Farbod, K. Cui, W. P. Kalisvaart, M. Kupsta, B. Zahiri, A.

45 Kohandehghan, E. M. Lotfabad, Z. Li, E. J.; Luber and D. Mitlin, ACS Nano, 2014, 8, 4415-4429.

38. A. Magasinski, P. Dixon, B. Hertzberg, A. Kvit, J. Ayala and G. Yushin, Nat. Mater, 2010, 9, 353-358.

39. I. Kovalenko, B. Zdyrko, A. Magasinski, B. Hertzberg, Z. Milicev, R. Burtovyy, I. Luzinov and G. Yushin, Science, 2011, 333, 75-79.

40. J. M. Mosby and A. L. Prieto, J. Am. Chem. Soc., 2008, 130, 1065610661 .

41. C.-H. Lai, K.-W. Huang, J. H. Cheng, C.-Y. Lee, B.-J. Hwang and L. J. Chen, J. Mater. Chem., 2010, 20, 6638-6645.

55 42. J. Huang, K. Wang and Z. Wei, J. Mater. Chem., 2011, 20, 1117 1121.

43. P. Simon and Y. Gogotsi, Nat. Mater., 2008, 7, 845-854. 